Indexed by:

Asinta



GARUDA

Crossref

crossmark

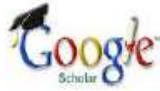

Dimensions

one

\author{
Muhammad Fadila Rais \\ Mahasiswa Arsitektur, FPTK \\ Universitas Pendidikan \\ Indoensia, Bandung, Indonesia \\ J1. Dr. Setiabudhi No. 207-229 bandung, \\ Indonesia 40154
}

Key words:

\title{
PERENCANAAN DAN PERANCANGAN KAWASAN SUPERBLOK JATINANGOR TEMA HIGH TECH ARCHITECTURE
}

\section{Donesearch \\ Manuscripts screening tools: \\ turniting

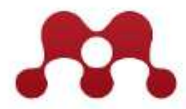 \\ MENDELEY}

Superblock, Jatinangor, High Tech Architecture

Doi:

10.17509/jaz.v4i1.27898

\section{Cite article:}

Rais, M. F., \& Yosita, L. (2021). Perencanaan dan Perancangan Kawasan Superblok Jatinangor Tema High Tech Architecture. Jurnal Arsitektur Zonasi, 4(1), 132-143. https://doi.org/doi.org/10.17509/jaz.v4i1.27898

Akses online:

untuk naskah lengkap tersedia di: https://ejournal.upi.edu/index.php/jaz/issue/archive

G grammarly 
http://ejournal.upi.edu/index.php/jaz - e-mail: jurnal_zonasi@upi.edu doi.org/10.17509/jaz.v4i1.27898

\section{PERENCANAAN DAN PERANCANGAN KAWASAN SUPERBLOK JATINANGOR TEMA HIGH TECH ARCHITECTURE}

\section{Article History: \\ First draft received: \\ 30 Agustus 2020 \\ Revised: \\ 5 November 2020 \\ Accepted: \\ 5 Desember 2020 \\ First online: \\ 3 Januari 2021 \\ Final proof received: \\ Print: \\ 1 Februari 2021 \\ Online \\ 6 Februari 2021}

Jurnal Arsitektur ZONASI

is indexed and listed in

several databases:

SINTA 4 (Arjuna)

GARUDA (Garda Rujukan Digital)

Google Scholar

Dimensions

oneSearch

BASE

\section{Member: \\ Crossref \\ RJI}

APTARI

FJA (Forum Jurna Arsitektur)

IAI

AJPKM

\author{
Muhammad Fadila Rais ${ }^{1}$ \\ Lucy Yosita ${ }^{2}$ \\ ${ }^{1}$ Universitas Pendidikan Indonesia, Bandung, Indonesia \\ Jln.Dr. Setiabudhi no.207-229 Bandung, 40154
}

Email: mfadilarais@gmail.com

lucyyosita@upi.edu

Abstract: Jatinangor Superblock is an integrated superblock complex located in the strategic area of Jatinangor education province. This design is based on the significant growth of the city in recent years. The development of satellite cities (hinterland) is one of the wise urban development concepts in overcoming the growth problems of the city of Bandung. Sumedang City as one of the hinterland cities, is trying to solve the development problem by providing increased development in the aspects of city facilities and infrastructure, settlements, offices, industry, worship, transportation and especially education. Jatinangor is one of the areas that has experienced significant regional development in Sumedang City. With the construction of the superblock in the Jatinangor sub-district it can encourage the growth of various activities in an integrated manner in an adequate container. This design aims to determine the facilities and facilities needed so that the occupants' activities can be well accommodated, Determine a good building layout in designing the Jatinangor Superblock, design the Jatinangor Superblock area which can be a solution to the problem of minimal land and mixed-used areas in urban areas and be a comfortable area and able to participate in building the surrounding area. In addition, this design also aims to resolve issues related to inadequate infrastructure so that they can be equipped so that the creativity and needs of building users can be fulfilled. The superblock design uses the High Tech Architecture theme. The application of the High Tech Architecture theme is quite flexible and can adjust the four functions contained in the Jatinangor superblock. With this planning and design, it is hoped that it will set a design precedent related to the superblock function.

\section{Keywords: Superblock, Jatinangor, High Tech Architecture}

Abstrak: Superblok Jatinangor merupakan kompleks superblok yang terintegrasi dan terletak di kawasan strategis provinsi pendidikan Jatinangor. Perancangan ini didasari dengan pertumbuhan kota yang signifikan dalam beberapa tahun terakhir. Pembangunan kota-kota satelit (hinterland) merupakan salah satu konsep pembangunan kota yang bijaksana dalam mengatasi permasalahan pertumbuhan kota Bandung. Kota Sumedang sebagai salah satu kota hinterland, berusaha mengatasi masalah pembangunan tersebut dengan memberikan peningkatan pembangunan pada aspek sarana dan prasarana kota, permukiman, perkantoran, industri, ibadah, transportasi dan terutama pendidikan. Kecamatan Jatinangor merupakan salah satu daerah yang mengalami perkembangan kawasan yang signifikan di Kota Sumedang. Dengan dibangunnya superblok di kecamatan jatinangor diharapkn dapat meningkatkan pertumbuhan kegiatan yang variatif secara terpadu dalam suatu wadah secara memadai. Perancangan ini bertujuan Menentukan fasilitas-fasilitas dan sarana yang dibutuhkan sehingga aktivitas penghuni dapat terwadahi dengan baik, Menentukan tata letak bangunan yang baik dalam merancang Superblok Jatinangor, merancang kawasan Superblok Jatinangor yang mampu menjadi solusi permasalahan minimnya lahan dan kawasan mixed-used di area perkotaan dan menjadi kawasan yang nyaman dan mampu turut membangun kawasan sekitarnya. Selain itu perancangan ini juga bertujuan untuk menyelesaikan isu isu yang berkaitan dengan sarana prasarana yang kurang memadai agar dapat dilengkapi sehingga kreatifitas dan kebutuhan dari pengguna bangunan dapat tercukupi. Perancangan superblok ini menggunakan tema High Tech Architecture. Penerapan tema High Tech Architecture cukup fleksibel dan dapat menyesuaikan empat fungsi yang terdapat di dalam superblok Jatinangor. Dengan perencanaan dan perancangan ini diharapkan agar menjadi preseden desain terkait fungsi superblok.

Kata kunci: Superblok, Jatinangor, High Tech Architecture 


\section{Pendahuluan}

\subsection{Latar Belakang}

Pertumbuhan kota yang cepat dalam beberapa dekade terakhir merupakan isu dan fenomena yang penting di Negara berkembang. Kota-kota besar di Indonesia seperti Jakarta, Surabaya, Semarang, Bandung, Medan, Makassar, dan Palembang mengalami perkembangan dan pertumbuhan yang pesat. Perkembangan dan pertumbuhan yang pesat tersebut diakibatkan oleh adanya arus urbanisasi. Bandung yang kini telah menjadi salah satu kota metropolitan di Indonesia memiliki tingkat urbanisasi yang tinggi. Hal demikian telah memberikan dampak tersendiri diantaranya seperti kemacetan, kemiskinan, dan pengangguran seolah merupakan hal biasa yang dijumpai. Berbagai kebijakan dan peraturan telah dirumuskan Pemerintah untuk mengatasi permasalahan tersebut telah mendorong kota-kota disekitar Bandung menanggung resiko dari pertumbuhan kota Bandung yang tak terkendali tersebut (urban sprawl). Mobilitas yang semakin pesat tidak dapat dihindari. Semakin meluasnya perkotaan semakin jauh pula jarak yang harus ditempuh oleh penduduk yang ditempuh untuk mencapai pusat kota yang notabennya adalah pusat segala aktivitas perekonomian kota, termasuk sarana dan prasarana kota yang dibutuhkan. Untuk itulah peningkatan mobilitas penduduk tersebut harus difasilitasi dengan pengadaan infrastruktur yang memadai.

Pembangunan kota-kota satelit (hinterland) merupakan salah satu konsep pembangunan kota yang bijaksana dalam mengatasi permasalahan kota Bandung tersebut. Kota Sumedang sebagai salah satu kota hinterland, berusaha mengatasi masalah pembangunan tersebut dengan memberikan peningkatan pembangunan pada aspek sarana dan prasarana kota, permukiman, perkantoran, industri, ibadah, transportasi dan terutama pendidikan. Salah satu kecamatan yang mengalami perubahan dan perkembangan kawasan yang cukup signifikan di kota Sumedang adalah kecamatan Jatinangor.

Jatinangor terletak di bagian Timur Kota Bandung tepatnya di Kabupaten Sumedeng, Provinsi Jawa Barat. Jatinangor termasuk ke dalam salah satu kecamatan dari 26 kecamatan yang dikenal sebagai daerah yang diperuntukkan sebagai daerah pendidikan di Jawa Barat karena pembangunan daerahnya yang difungsikan sebagai institusi dan universitas, seperti Universitas Padjadjaran (Unpad), Institut Pemerintahan Dalam Negeri (IPDN), Institut Koperasi Indonesia (Ikopin), dan Institut Teknologi Bandung (ITB). Dipilihnya Jatinangor sebagai Kawasan Pendidikan di Jawa Barat membawa dampak positif. Salah satunya berdampak positif pada sektor konstruksi. Hal ini dapat kita lihat bagaimana hanya dalam beberapa waktu terakhir perkembangan jatinangor sudah semakin pesat dengan dibangunnya mall, apartemen, juga infrastruktur yang terus menerus dibenahi.

Perkembangan di daerah Jatinangor ini juga mengakibatkan Jatinangor mengalami kepadatan penduduk dan semakin berkurangnya ketersediaan lahan. Dengan sedikitnya ketersediaan lahan membuat harga tanah semakin tinggi. Hal ini yang memicu para perancang untuk membuat suatu kawasan yang efektif dan memiliki banyak fungsi, salah satunya adalah dengan pembangunan superblok.

Pengembangan kawasan berbasis superblok merupakan salah satu dari banyaknya cara untuk mengembangkan pembangunan yang efisien karena dapat mengakomodasi kepadatan yang tinggi dengan konsep bangunan vertikal. Di Indonesia pembangunan menggunakan konsep superblok menjadi populer diawal tahun 80-an (Ernawati, 2010). Pembangunan kawasan superblok merupakan pembangunan yang didalamnya diisi oleh massa bangunan yang menawarkan efektivitas kebutuhan seperti hunian, perhotelan, gedung dan perkanntoran, dan sekolah yang secara visual terlihat sangat modern dan mewah dalam segala hal baik tampilan maupun sosial dan lingkungan yang ditawarkan. Berdasarkan karakteristik tersebut, ketersediaan superblok pada suatu kota khususnya.

Konsep superblok didukung oleh berbagai keuntungan, paling sedikit terdapat enam keuntungan dari konsep superblock, diantaranya: mendorong tumbuhnya kegiatan yang beragam secara terpadu dalam suatu wadah secara memadai; menghasilkan efisiensi terhadap system sarana, prasarana dan ekonomi; memperbaiki sistem sirkulasi; meningkatkan perkembangan sistem persil yang lebih fleksibel; pengembangan moda transportasi yang lebih jelas dan terstruktur berdasarkan kategorinya; dan memberikan konsep atau proses pemikiran yang luas terhadap inovasi perancangan bangunan dan lingkungan (Danisworo, 1996).

\subsection{Tujuan dan Sasaran Perancangan}

Perancangan Kawasan Superblok Jatinangor ini memiliki beberapa tujuan, yaitu:

1. Menentukan fasilitas-fasilitas dan sarana yang dibutuhkan sehingga aktivitas penghuni dapat terwadahi dengan baik.

2. Menentukan tata letak bangunan yang baik dalam merancang Superblok Jatinangor. 
3. Merancang kawasan Superblok Jatinangor yang mampu menjadi solusi permasalahan minimnya lahan dan kawasan mixed-used di area perkotaan.

4. Menjadi kawasan yang nyaman dan mampu turut membangun kawasan sekitarnya.

Sasaran yang dituju dalam Perancangan Kawasan Superblok Jatinangor ini antara lain:

1. Kecamatan Jatinangor, sebagai penyedia lahan

2. Industri/Swasta, bertindak sebagai penyedia infrastruktur kawasan, pemilik modal/investor, penyedia barang yang dibutuhkan, pelatihan sdm,dll

3. Masyarakat, sebagai penggerak utama lembaga dan penyedia SDM.

\section{Metode Penelitian dan Perancangan}

Metode perancangan adalah suatu cara yang dilakukan pada sebuah proses perancangan, metode ini dibutuhkan untuk mempermudah perancang dalam melakukan perancangannya. Dalam proses perancangan kawasan Superblok ini, metode yang digunakan adalah metode penelitian dan perancangan (Research and Development) dan analisisi deskriptif kuantitatif-kualitatif.

Menurut Hanafi (2017), metode penelitian dan pengembangan atau Research and Development (R\&D) adalah metode penelitian yang digunakan untuk menghasilkan produk tertentu dan menguji keefektifan metode tersebut. Dalam bidang arsitektur, Research and Development (R\&D), merupakan metode penelitian yang digunakan untuk mengembangkan atau memvalidasi desain yang bertujuan untuk menguji validitas dan keefektifan produk tersebut dalam penerapannya. Metode penelitian dan pengembangan merupakan sebuah proses, usaha dan strategi untuk meningkatkan praktek sebagai penguji keabsahan dan pengembangan sebuah produk (Haryati, 2012). Proses dari metode ini disebut dengan siklus R\&D yang terdiri dari mempelajari temuan yang berkaitan dengan produk yang akan dikembangkan, mengembangkan produk berdasarkan temuan, pengujian dan pengaturan yang pada akhirnya produk ini akan digunakan, dan memperbaiki kekurangan yang ditemukan dalam tahap pengujuan. Dalam proyek ini, produk yang dimaksud adalah kawasan superblok dan temuan yang dimaksud adalah permasalahan yang ada pada kawasan superblok, sedangkan pengujian dan pengaturan adalah menentukan tema dan konsep yang cocok dan berkaitan dengan superblok yang memiliki berbagai macam permasalahan desain yang perlu diperbaiki. Dengan melakukan riset berdasarkan preseden yang ada, maka akan ditemukan sebuah gagasan atau ide perancangan baru yang kemudian dapat dikembangkan lagi.

Selain itu, metode pengumpulan data dibagi menjadi dua jenis yaitu data primer dan data sekunder. Data primer merupakan data yang diambil melalui wawancara dengan narasumber terkait sebagai tujuan untuk mendapatkan informasi yang solid. Observasi atau survei lapangan, dengan tujuan untuk memperoleh gambaran tetntang ruang dan fasilitas yang dibutuhkan, persyaratan dan standar ruang, serta persyaratan khusus pada ruang ruang tertentu. Data sekunder didapat dengan mengumpulkan data dari berbagai kajian literature, terutama mengenai beberapa hal yang berkaitan dengan legal aspek, regulasi, hingga persyaratan ruang, maupun persyaratan bangunan di Kecamatan Jatinangor. Sebagai landasan yang tepat. Pembahasan menggunakan pendekatan teoritis dan pendekatan studi, yang mana melengkapi data dari wawancaran dan observasi. Hasil dari pendekatan tersbut akan dikembangkan untuk mendapatkan konsep perencanaan dan perancangan arsitektur.

\section{Kajian Teori}

\subsection{Judul Proyek}

Proyek dengan judul "Superblok Jatinangor" merupakan kompleks superblok yang terintegrasi dan terletak di kawasan strategis Provinsi Pendidikan Jatinangor. Superblok ini berlokasi di Jalan Raya Jatinangor, Cibeusi, Jatinangor dengan luasan lahan $3 \mathrm{Ha}$ dan terletak di zonasi perdagangan dan jasa (ungu k-1), superblok ini dapat menjangkau segala kebutuhan masyarakat yang tinggal di kawasan ini seperti kebutuhan tempat belanja, tempat menginap, hotel dan kantor.

\subsection{Studi Literatur}

\subsubsection{Superblok}

Superblok merupakan suatu kawasan di konteks urban yang dirancang secara terpadu dan terintegrasi dalam memaksimalkan fungsi lahan. Pembangunan kota saat ini umumnya berupa pembangunan superblok yang dapat memecahkan permasalahan karena keterbatasan lahan di kawasan perkotaan (Azalia, 2019). 
Sesuai dengan Panduan Rancangan Kota (Dinas Tata Kota, 1984) kawasan multifungsi atau superblock terpadu memiliki luas minimal 2 hektar dengan satu atau lebih peruntukkannya, harus dibatasi oleh sekurangkurangnya dua buah jalan kolektor atau sebuah jalan kolektor dengan prasarana lain sejenis atau setingkat.

Suatu bentuk / wadah fisik dari pengembangan Mixed-Use Development, dapat diartikan sebagai suatu blok atau massa bangunan yang berbeda dalam fungsi tetapi saling mendukung antara satu sama lainnya. (Urbanland Insitute, Mixed-Use Development Hand Book, Washington D.C, 1987).

Karakteristik pada kawasan multifungsi atau superblock terpadu adalah fungsi permukiman atau fungsi komersial atau bisnis yang luas dikelilingi oleh jalur pejalan kaki dan kadangkala akses masuknya ditandai oleh ruang hijau (landscape) atau ruang terbuka. (Webster, Merriam Third New Dictionary, Massachussets, USA, 1986).

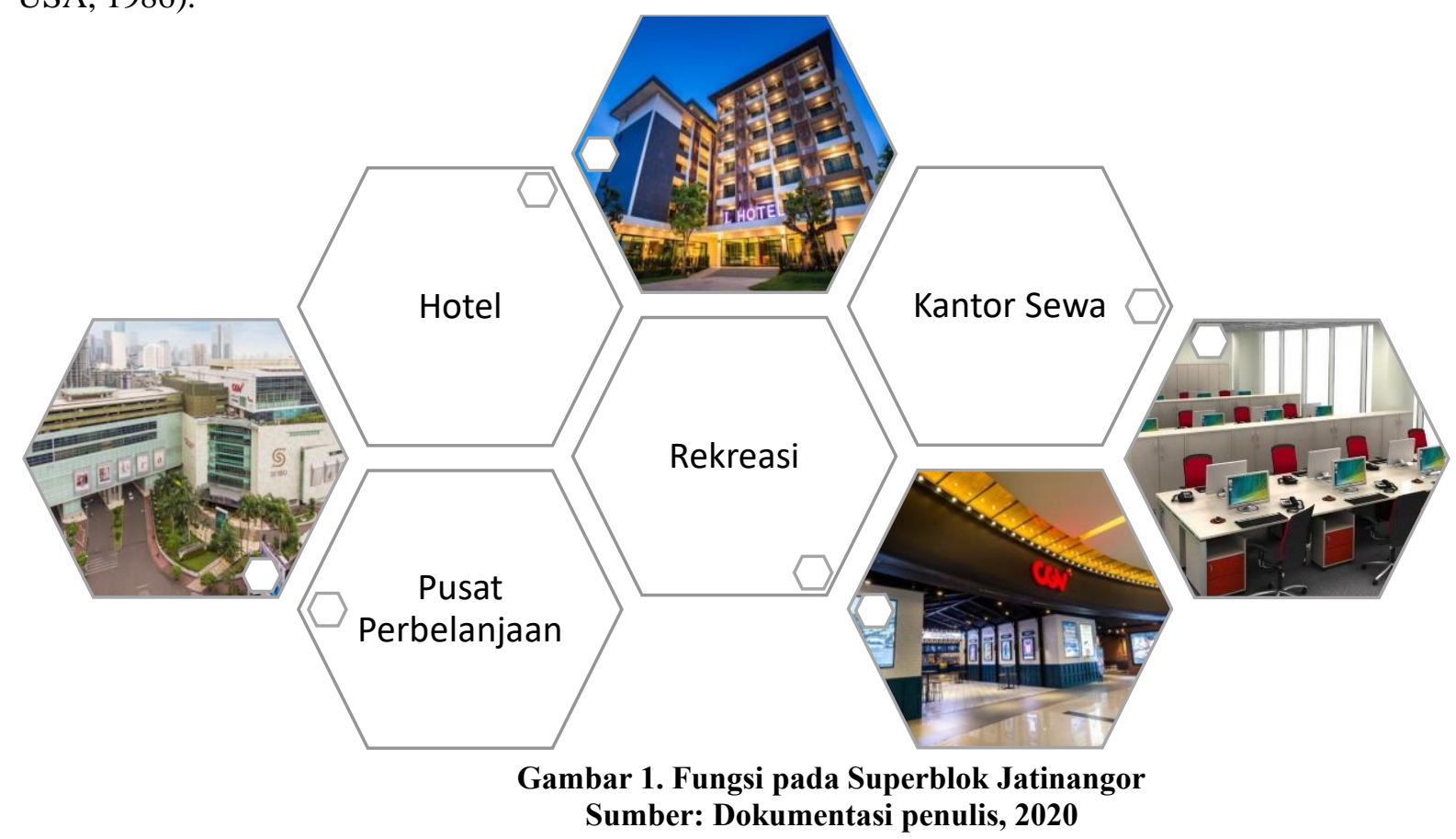

\subsection{Elaborasi Tema}

\subsubsection{Pengertian High Tech Architecture}

High Tech dalam arsitektur diartikan sebagai suatu gaya atau prinsip arsitektur yang pada awalnya berkembang dari gaya atau prinsip gerakan arsitektur modern yang mengutamakan kesan struktur dan teknologi suatu bangunan. Karakteristik pada bangunan arsitektur high tech adalah bangunannya yang menggunakan material sintetis seperti logam, kaca dan plastik (Davies, 1989).

Arsitektur High Tech adalah sebuah gaya atau prinsip arsitektur yang muncul pada sekitar tahun 1970an, kemudian pada akhir abad ke-20 arsitektur hi-tech dikenal sebagai Modernisme Akhir atau Ekspresionisme Struktural. Prinsip ini muncul sebagai modernism yang seiring waktu mengalami perubahan ide dalam teknologinya dan muncul sebagai transisi dari modernism dan post-modernisme (Bahar, 2010). Pada 1980an, Arsitektur High Tech memiliki makna dan perbedaan yang bias dari arsitektur post-modern karena lahir dari berbagai tema dan ide yang diserap ke dalam Bahasa arsitektur pasca-modern.

Menurut Kuhlmann (2011), arsitektur high-tech sebagai sebuah langgam arsitektur dengan penerapan teknologi inovatif dan memiliki kesan visual kuat, memiliki metode yang dipergunakan dalam melakukan pencarian bentuk yang berakar pada konsep organicism, selanjutnya disebut arsitektur bionik. Pada prinsipnya, arsitektur High Tech menggabungkan elemen dan prinsip dari industri dan sistem berteknologi tinggi ke dalam desain bangunan.

\subsubsection{Aplikasi Perancangan Karya Norman Foster}

Norman Foster sebagai salah satu pelopor arsitektur high tech, mampu memvisualisasikan bangunan yang memiliki ciri tersendiri. Berikut merupakan ciri khas karya Norman Foster yaitu:

1. Struktur dan konstruksi yang diekspos;

2. Menampilkan bagian dalam bangunan yang mempunyai nilai sama pada bagian luar bangunan;

3. Fasad bangunan yang transparan sehingga bagian interior terekspos dan dapat dilihat dari luar;

4. Bagian dalam bangunan yang dirancangan dengan kontras sehingga dijadikan sebagai ornament atau sculpture 
Dengan demikian, dapat dipahami bagaimana suatu proses penyelesaian terapan konstruksi, gaya bekerja, dan bahan bangunan dirancang secara logis. Selain itu, banyak dari karya Norman Foster yang bangunannya dilapisi oleh unsur transparan pada dinding luarnya, lapisan struktur dengan warna abu-abu, pelapisan pipa-pipa saluran, tangga, eskalator, lift, dengan warna silver metalik yang dengan begitu menghasilkan karakteristik bangunan high tech.

\subsubsection{Prinsip Perancangan High Tech Architecture (Collin Davies)}

Prinsip Perancangan Arsitektur High Tech menurut Collin Davies:

1. Fleksibitas Ruang

Menggunakan fungsi fleksibilitas dan kemudahan operasional ruang. Berbagai elemen dari suatu bangunan yang berasitektur High Tech, seperti struktur baja yang kekar, kulit bangunan yang licin, dan pipa-pipa hphng diekpose adalah suatu expresi dalam memenuhi fungsi teknis bentuk keseluruhan dari fungsi bangunan tersebut. Biasanya suatu bentuk bangunan ini kurang mampu untuk mengekpresikan fungsi bangunan yang ada didalam, missal tampak bangunan dari luar itu sangat rumit tapi untuk pembagian ruang dan sirkulasi sangat sederhana.

2. Penggunaan Plug-In Plot

Penggunaan komponen plug in fabrikasi dirakit pada bangunan sehingga menghasilkan modul-modul yang serupa, seperti modul toilet atau modul rangka struktur. Hal tersebut didasari oleh kemajuan teknologi sehingga menghasilkan system yang praktis dalam pembangunan sebuah bangunan. Selain itu, komponen plug in pod dapat diperbaharui dengan plug in yang baru.

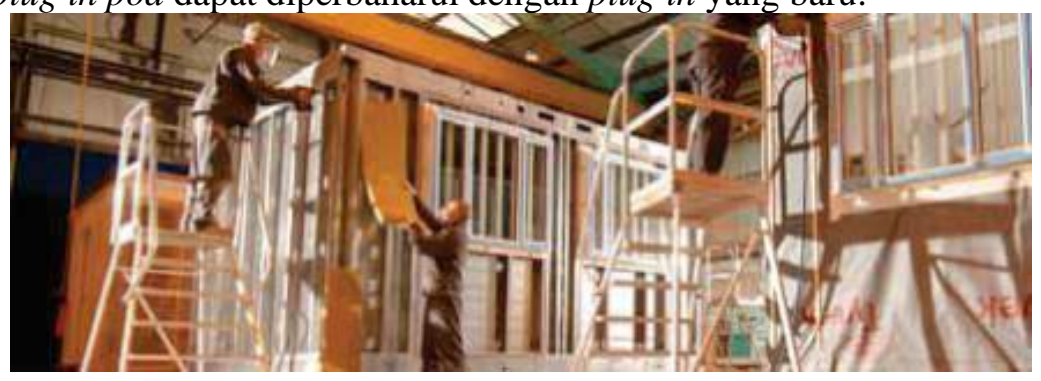

Gambar 2. Bangunan Plug in Pod

Sumber: Terrapinggrup.co.uk/pluginpod/

3. Menggunakan bahan yang mengacu pada kecanggihan teknologi

Hal tersebut merupakan penerapan karakteristik arsitektur High Tech, kedepan mungkin digunakan barang-barang terbaru, sehingga bangunan agar terkesan berteknologi tinggi tetepi terpelihara. Bahan yang canggih ini berupa aluminium, baja, plastic, neoprene, serta produk-produk lainnya. Bahanbahan ini tidak terdapat kecanggihannya, tetapi hanya kesan canggih.Hal tersebut disebabkan oleh kesan bentuk, mutu, dan finishing bahan, compost dan sebagainya.

4. Sistem-sistem bangunan menggunakan teknologi terbaru

Sistem bangunan juga menggunakan bahan-bahan yang terbaru yang belum ada sebelumnya. Meliputi sistem struktur yang lebih efektif dan efisien dalam penyaluran bahan dan pengunaan bahan yang lebih sedikit, sistem penerangan alami, pencahayaan dan penanggulangan kebakaran dan lain-lain.Tentu saja merupakan suatu hal yang ironi, jika bahan-bahan yang digunakan tercanggih.

5. Berdasarkan teknologi industri bukan sekedar tradisi dalam berasitektur

Teknologi industry menghasilkan produk-produk massal dengan mutu yang tinggi dan hasil akhir yang seragam. Di dunia ini hampir tidak ada bangunan yang diproduksi massal kecuali komponenkomponennya. Ini lah yang menjadi dasar arsitektur High Tech yang menjadi produk industri.

\subsubsection{Karakteristik High Tech Architecture (Charles Jenks)}

Charles Jenks (1988) menuliskan 6 karakteristik high tech building, yaitu sebagai berikut:

\section{Inside out}

Dalam hal ini yang dimaksud adalah bagian interior yang biasanya tertutup dengan tembok atau material penutup lainnya kemudian pada prinsip High Tech ini diperlihatkan keluar dengan penggunaan material yang transparan, seperti kaca. Fungsi-fungsi yang umumnya tertutup/ditutupi kemudian diperlihatkan visual interiornya, seperti fungsi servis dan utilitas. 


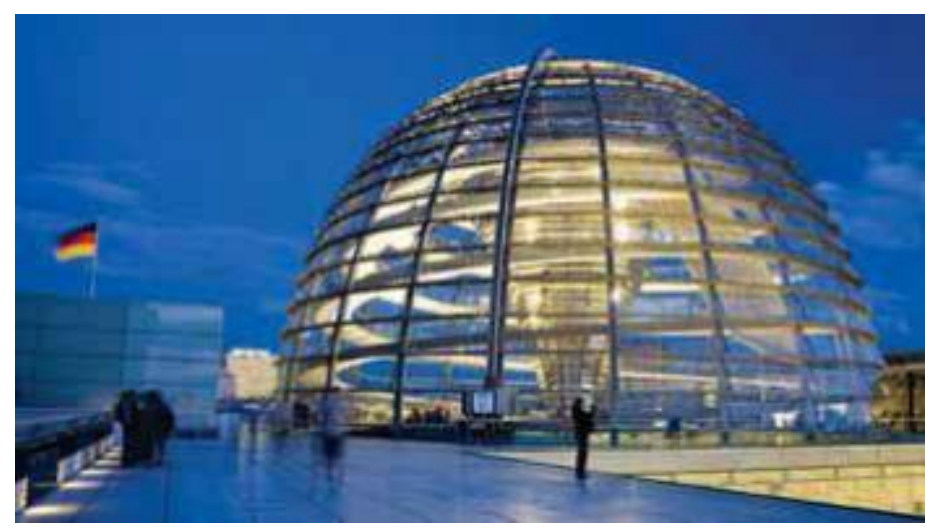

Gambar 3. Reichtag dome karya Norman Foster

Sumber: OpenBuilding.com/reichtagDome/

2. Celebration of process

Penegasan pemahaman tentang bagaimana, mengapa, dan apa dari konstruksi sebuah bangunan. Contohnya yaitu sebuah penilaian oleh Charles Jenks mengenai Norman Foster. Karya Norman Foster memiliki ciri khas yang mampu memberikan kesan dan dapat mengungkapkan sesuatu yang berbeda dari karya arsitek lainnya. Proses dan ide yang dikembangkan pada sebuah rancangan bangunan dapat disesuaikan oleh Norman Foster sesuai dengan zamannya sehingga karyanya memiliki fungsi dan fasad bangunan yang menjadi satu kesatuan dan memiliki mekanisme dan sistem bangunan yang sempurna.

3. Transparancy, Layering, and Movement

Karakteristik ini menjadi kualitas keindahan yang hampir selalu ditonjolkan secara dramatis tanpa terkecuali. Selain itu, penggunaan material kaca, material lapisan pipa saluran, material dan struktur tangga, serta penekanan pada escalator dan lift menjadi elemen bergerak yang merupakan karateristik lain dari bangunan high-tech. Menurut Forilma (2016), penerapan parameter transparency, layering dan movement, dapat diaplikasikan melalui penggunaan warna material cerah, ekspos struktur dengan aplikasi struktur ringan serta penyatuan antara ruang luar dan dalam.

4. Pewarnaan yang cerah dan merata

Karakteristik ini bertujuan untuk memberikan perbedaan yang kontras terhadap struktur dan utilitas bangunan serta memudahkan teknisi dalam membedakan dan memahami penggunaannya secara efektif. Contohnya pada karya Richard Rogers yaitu bangunan Pampidou Center dan Inmos Factory yang menggunakan warna-warna cerah.

5. A light weight filigree of tensile members

Baja tipis sebagai penopang atau kolom, serta kelompok kabel baja penopang dapat membuat bangunan menjadi lebih ekspresif dalam ide atau gagasan mengenai pengaplikasian gaya atau prinsip high tech pada struktur.

6. Optimistic confidence in a scientific cultura

High-tech building adalah sebuah perubahan masa depan yang diyakini dapat menjadi ciri masa depan, yakni kebudayaan/peradaban masa depan yang serba scientific, sehingga pada saat itu tetap bisa dipakai dan tidak ketinggalan zaman. Hasil rancangan bangunannya lebih mendalam pada metode kerja yang lebih efisien dan efektif, penggunaan material yang inovatif, pemilihan warna yang sesuai, dibandingkan dengan prinsip-prinsip komposisi. Menurut Rahayu (2017), perwujudan konsep perancangan berdasarkan Optimistic Confidence in Scientific Culture dapat diterapkan melalui perlakuan warna-warna pada bangunan, material, dan wujud yang dapat memberikan preseden di masa mendatang.

Jadi dapat disimpulkan Arsitektur high tech memiliki ciri -ciri sebagai berikut:

- Berestetika mesin

- Menggunakan material logam ataupun material penemuan baru

- Fasad atau bentuk bangunan merupakan hasil sebuah ekspresi perancangnya dibandingkan fungsi bangunan

- Struktur, konstruksi, maupun sistemnya menggunakan teknologi tinggi atau terbarukan 
Arsitektur high tech tidak terlepas dari kesan futuristic dengan karakter sebagai berikut:

- Konsep bangunan mengutamakan visi masa kini atau masa depan

- Estetika mesin yang mencerminkan era industrialisasi

- Penggunanan bahan prefabrikasi dan bahan-bahan baru lainnya

- Bentuk yang variatif, fleksibel, dan inovatif (tidak konvensional lagi)

\section{Hasil dan Pembahasan}

\subsection{Perencanaan dan Perancangan Superblok}

\subsubsection{Latar Belakang Lokasi}

Kondisi tapak dengan eksisting sebagian besar lahan kosong, yang terletak di Kawasan Strategis Provinsi (KSP) Pendidikan. Kawasan ini terbilang sangat strategis karena dikelilingi banyak Universitas ternama, ditambah lokasinya yang tidak terlalu jauh dengan pusat pelayanan kota dan tentunya akan megundang atensi para warga asli maupun warga pendatang ketika terjadi pengembangan kawasan dengan hadirnya Superblok dimana akan adanya hunian yang terintegrasi langsung dengan area pusat perbelanjaan, tetntunya hal ini akan menjadi perhatian masyarakat untuk berinvestasi dalam bidang properti.

\subsubsection{Konsep Rancangan Tapak (Zoning Makro)}

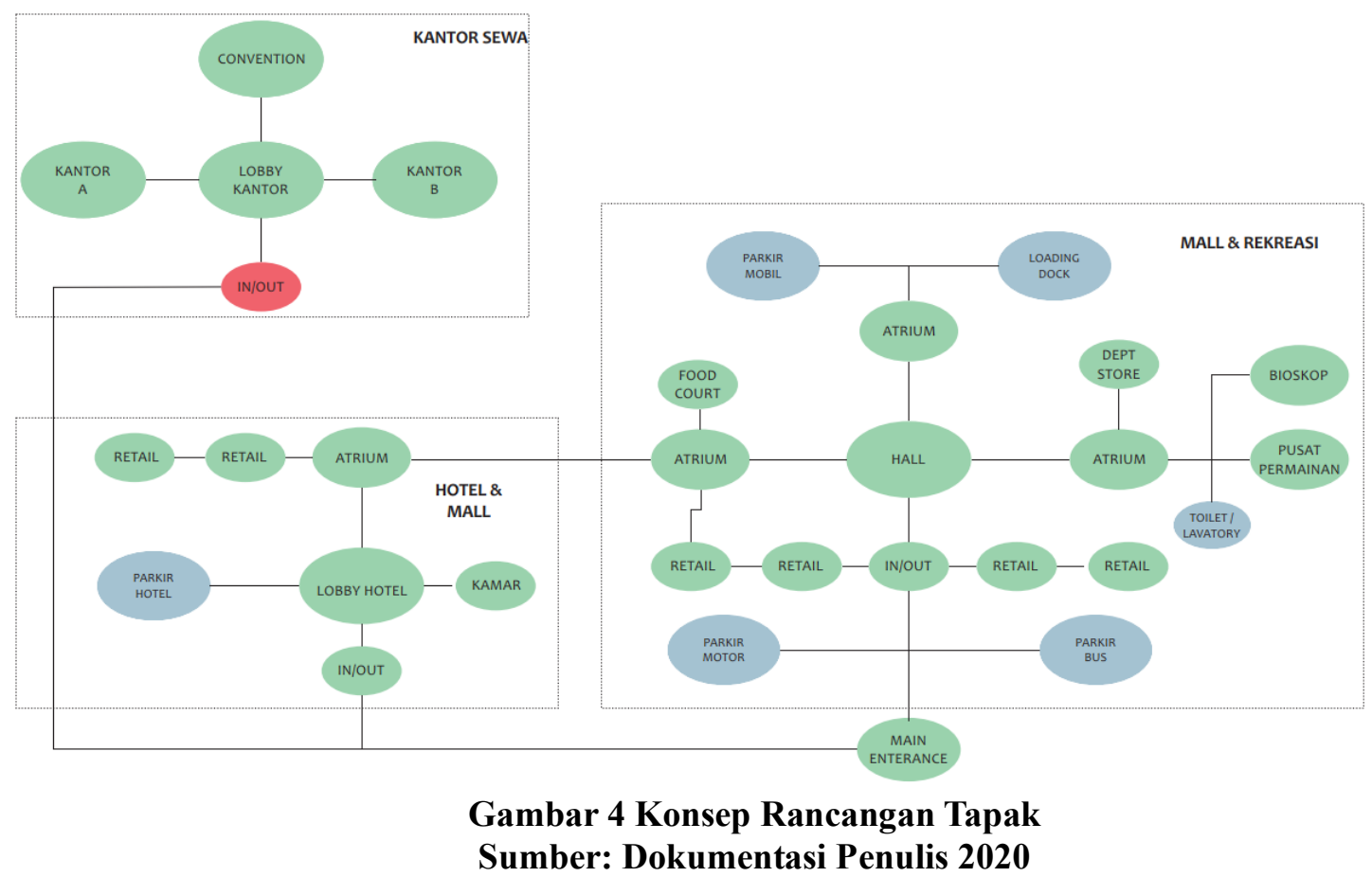

Superblok terbagi akan tiga bangunan utama dengan empat fungsi. Bangunan pertama yaitu Jatinangor Shopping Center (JSC) mall barat yang terdapat fungsi mall dan rekreasi. Kemudian, bangunan kedua yaitu Jatinangor Shopping Center (JSC) mall timur terdapat fungsi Hotel dan mall. Bangunan ketiga yaitu berfungsi sebagai Kantor Sewa. 


\subsubsection{Konsep Zonasi Tapak}

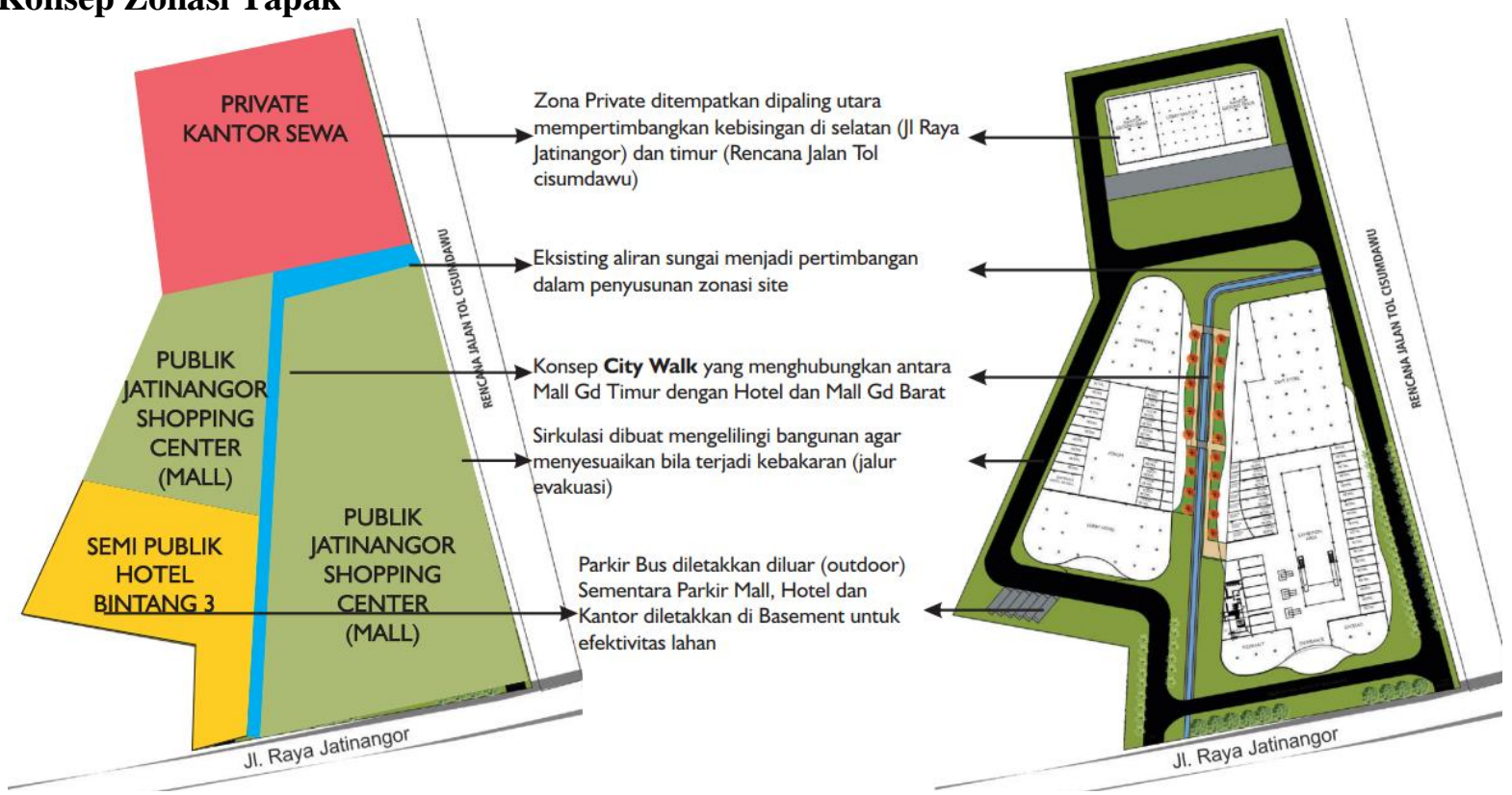

Gambar 5. Konsep Zonasi Tapak

Sumber: Dokumentasi Penulis 2020

Zonasi Tapak dibagi menjadi tiga zona berdasarkan sifat ruang. Selain itu tapak terbagi oleh sungai eksisting. Pada main enterance terdapat pusat perbelanjaan dan rekreasi berupa bioskop. Kemudian pada side enterance difungsikan sebagai enterance hotel yang bersifat semi publik. Zona private yang terdapat kantor ditempatkan pada bagian belakang site dengan mempertimbangkan kebisingan di Jl Raya Jatinangor.

\subsubsection{Konsep Rancang Bentuk}

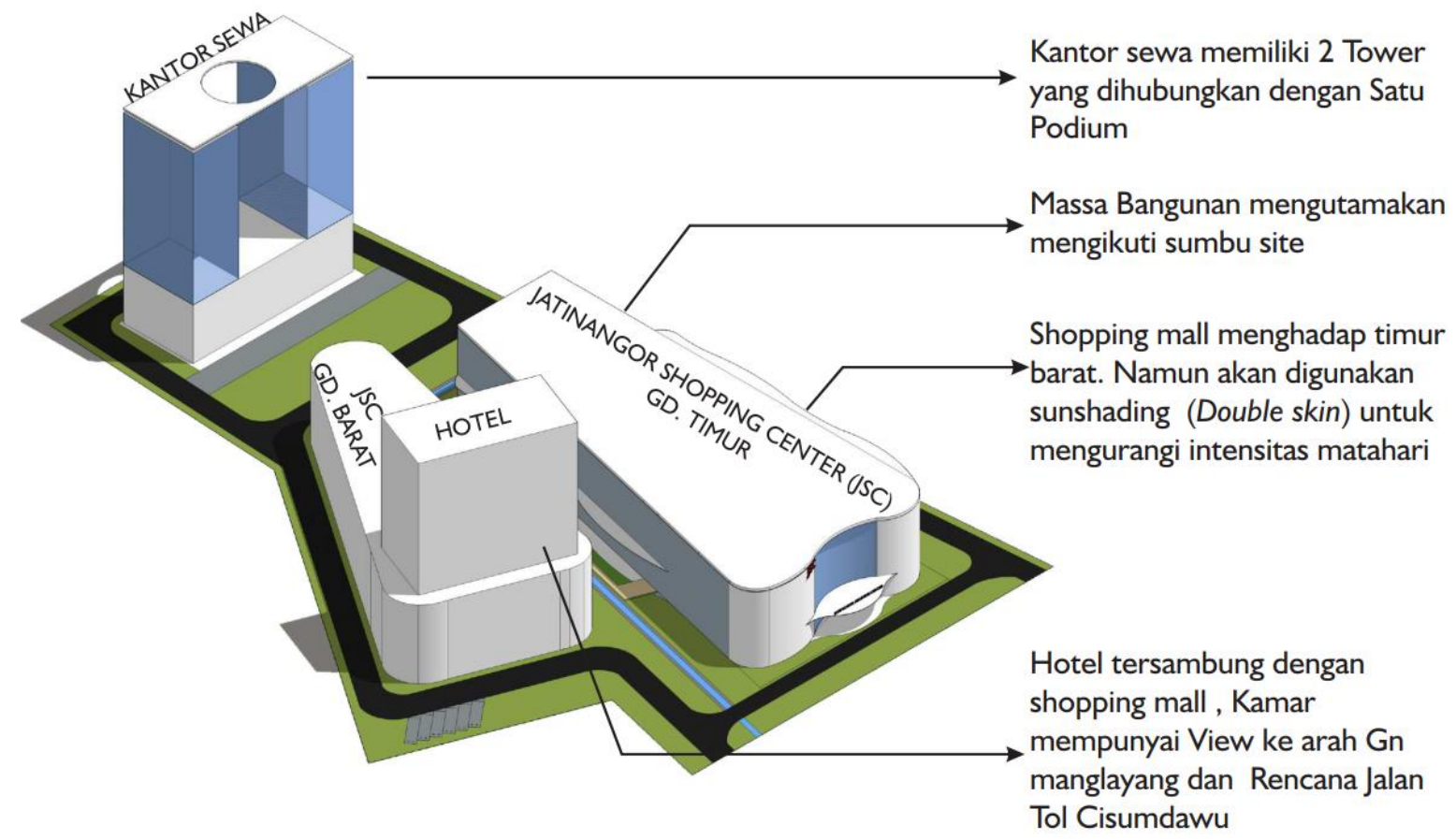

Gambar 6 Konsep Rancang Bentuk

Sumber: Dokumentasi Penulis 2020

Massa bangunan mengutamakan mengikuti sumbu site yang juga terbagi oleh sungai eksisting. Perletakkan massa bangunan juga berorientasi pada view. 


\subsubsection{Konsep Rancangan Struktur}
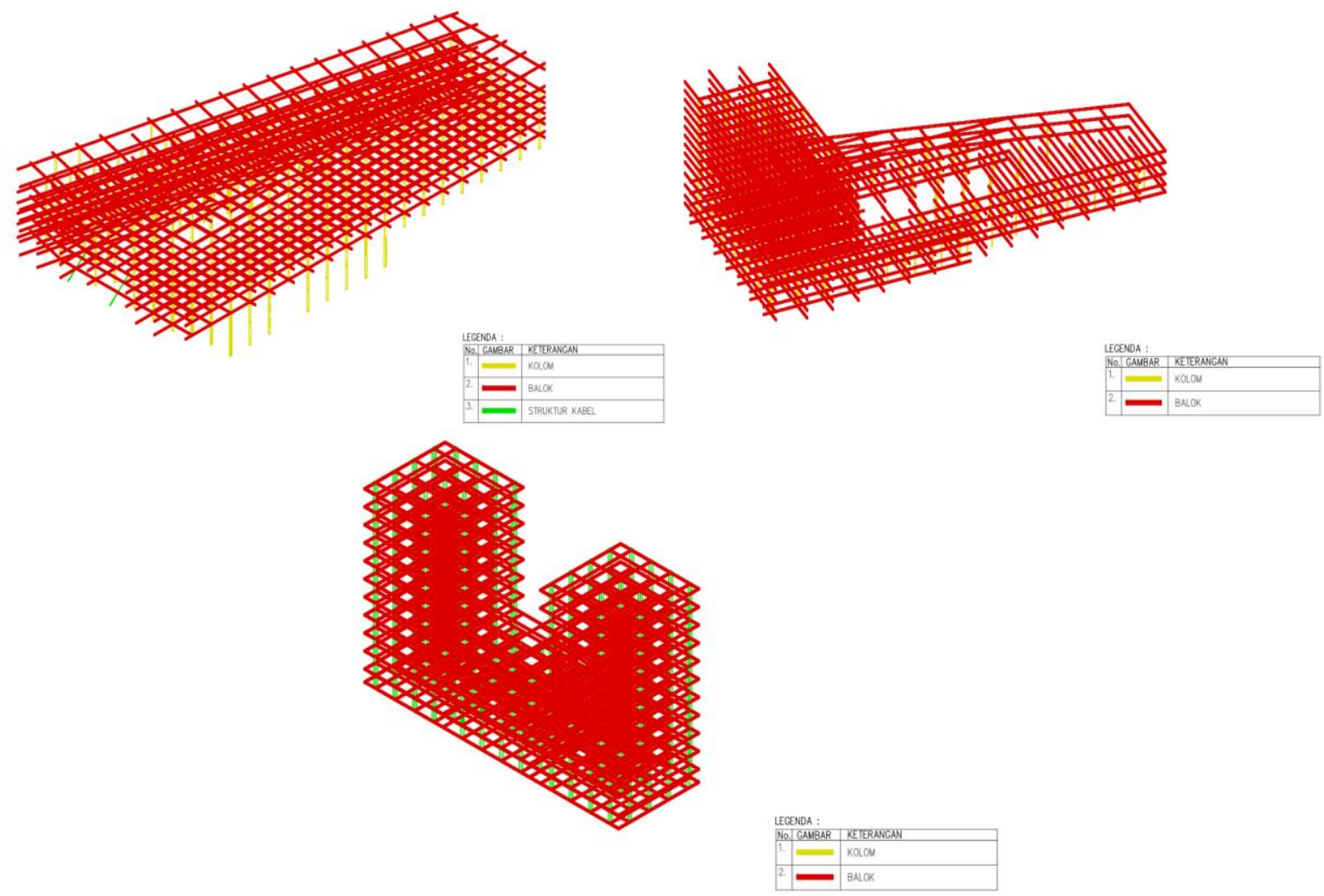

Gambar 7. Sistem Struktur

\section{Sumber: Dokumentasi Penulis 2020}

Sistem struktur menggunakan sistem Rigid Frame yang mana sistem ini terdiri dari kolom dan balok yang bekerja saling mengikat satu degan yang lainnya. Kolom berfungsi sebagai unsur vertikal untuk menerima beban dan gaya, sedangkan balok berfungsi sebagai unsur horizontal untuk media pembagi beban dan gaya. Biasanya pola grid persegi diimplemetasikan pada system ini, hubungan antar grid serupa juga digunakan pada bidang horizontal yang terdiri atas balok dan gelagar. dengan keterpaduan rangka spasial yang bergantukng pada kekuatan kolom dan balok, maka tinggi lantai ke lantai dan jarak antara kolom menjadi penentu pertimbangan perancangan.

\subsection{Aplikasi High Tech Architecture}

\subsubsection{Inside Out}

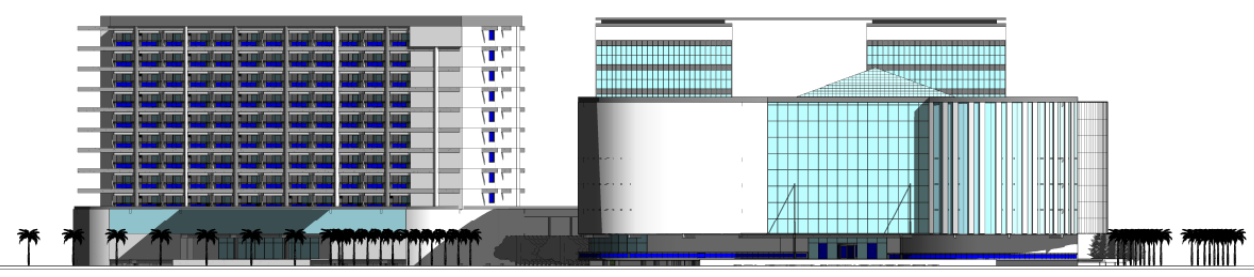

Gambar 8. Penerapan Inside Out dalam Superblok Jatinangor Sumber: Dokumentasi Penulis 2020

Dengan penggunaan banyak kaca, bangunan cenderung menampilkan bagian dalam yang dapat dilihat dari luar bangunan. Pada atap bangunan juga menggunakan banyak kaca. 


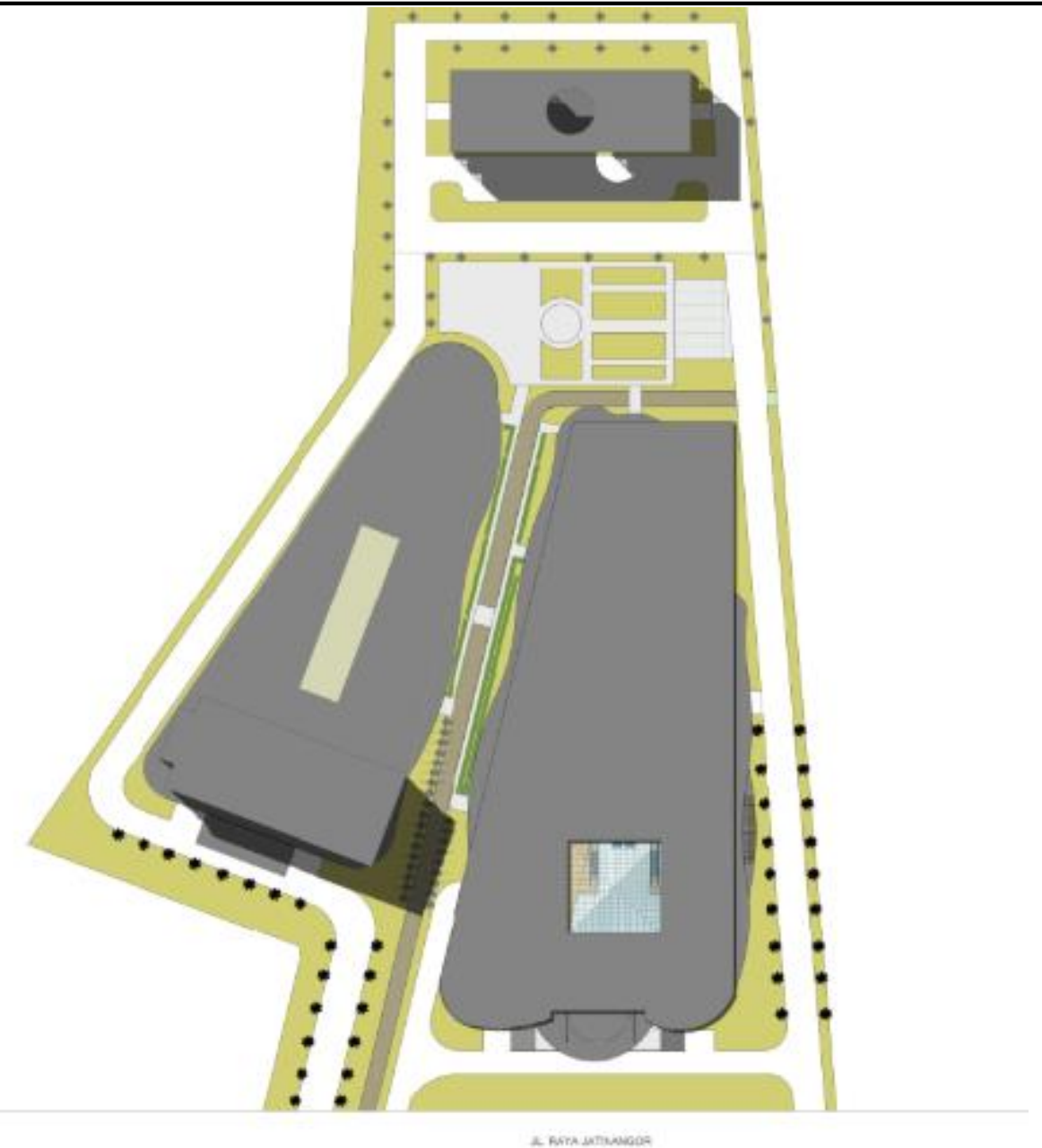

Gambar 9. Site Plan

Sumber: Dokumentasi Penulis 2020

\subsubsection{Celebration of process}

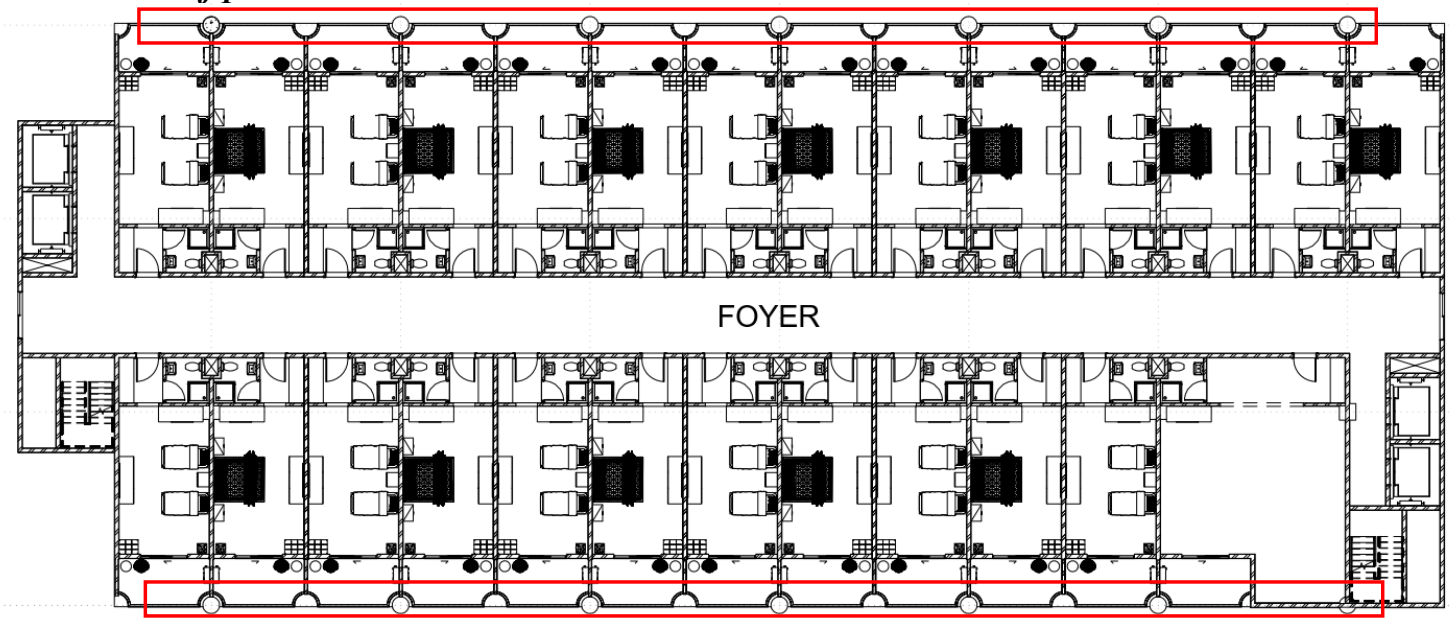

Gambar 10. Penerapan Celebration of Process dalam Superblok Jatinangor Sumber: Dokumentasi Penulis 2020

Penekanan terhadap kontruksi dapat dilihat pada bangunan hotel dimana kolom diletakkan diluar bangunan sehingga dapat menjadi estetika tersendiri dari tampak bangunan. 
4.2.3 Transparancy, Layering, and Movement

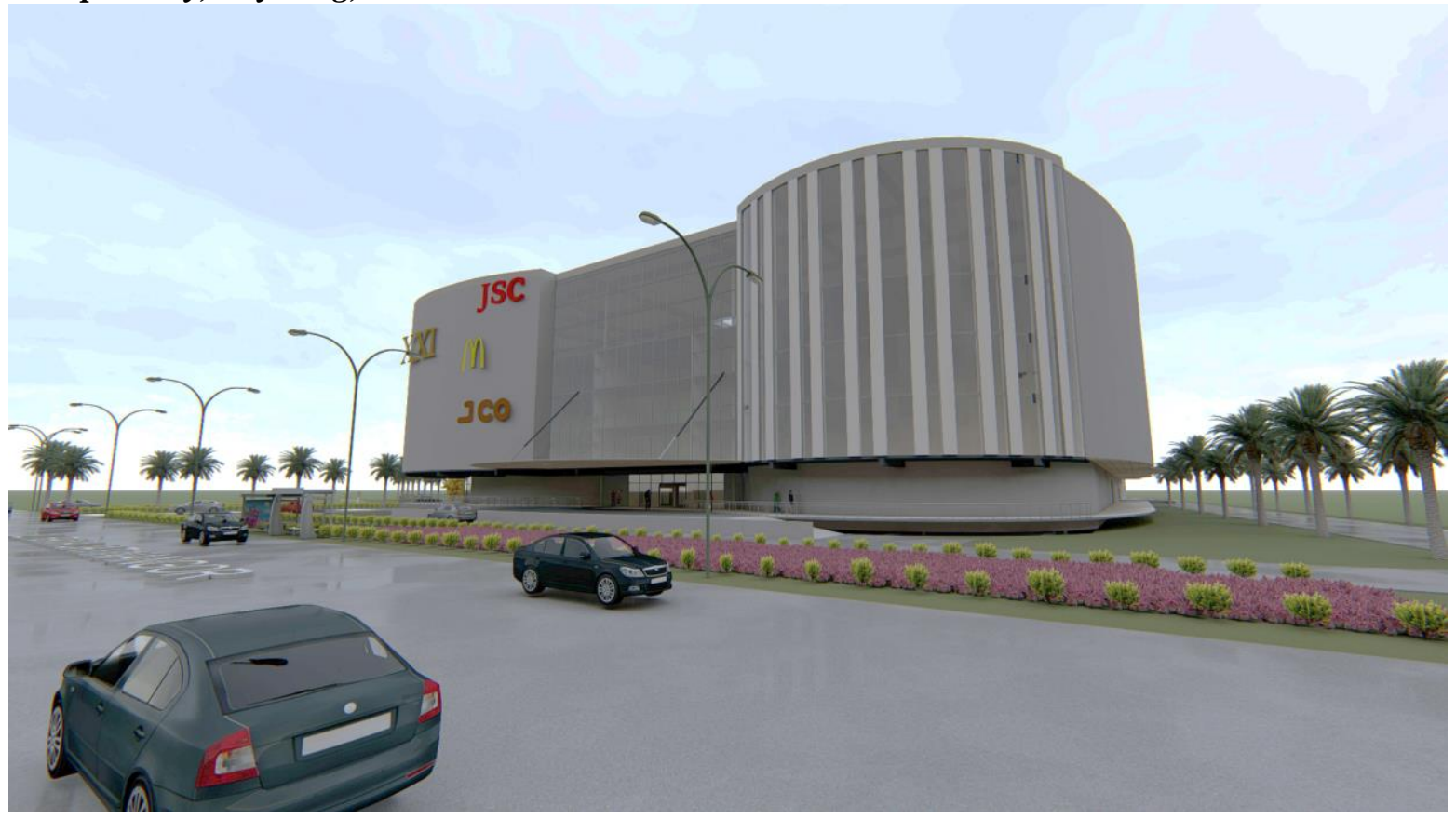

Gambar 11. Tampak Bangunan

Sumber: Dokumentasi Penulis 2020

Tampilan bangunan banyak menggunakan kaca. Hal ini dikarenakan Kompleks Superblok menggunakan tema High Tech Architecture. Salah satu parameternya adalah Transparancy, Layering, and Movement. Perancangan berdasarkan parameter tersebut diterapkan melalui bukaan yang lebar sehingga memberi kesan bebas dan luas. Kesan tersebut diimplementasikan ke dalam materil penutup bangunan seperti kaca yang dapat dilihat dari dalam bangunan tetapi tidak dari luar bangunan.

\section{Kesimpulan}

Superblok Jatinangor mampu menjadi solusi permasalahan minimnya lahan di area perkotaan. Sebagai kawasan mixed-used superblok mampu mewadahi aktivitas dengan menempatkan berbagai macam fungsi pada satu kawasan. Superblok pada Kecamatan Jatinangor ini juga dirancang untuk dapat memenuhi sasaran perancangan agar dapat mendatangkan investor juga pengunjung baik masyarakat Kecamatan Jatinangor maupun pendatang.

High Tech Architecture dapat membuat Kawasan Superblok Jatinangor terintegrasi secara tampilan dan tema perancangan. Beberapa karakteristik yang digunakan pada perancangan superblok ini yaitu, inside out, celebration of process, dan Transparancy, Layering, and Movement. Penggunaan ketiga karakteristik tersebut membuat bangunan terkesan lebih modern dengan banyak penggunaan kaca, kolom yang terkespos diluar bangunan, penggunaan struktur kabel, penggunaan struktur baja pada bentang lebar, sistem utilitas yang terkespos, penggunaan interior industrial, dan lain-lain. Tema High Tech Architecture ini juga yang mampu membuat bangunan mudah dalam segi maintenance nya karena struktur dan utilitas yang dibuat terekspos.

\section{Referensi}

Azalia, S. K. (2019). Studi Iklim Mikro Pada Ruang Terbuka Hijau Kawasan Superblok Di Rasuna Epicentrum, Jakarta Selatan.

Bahar, M. A. (2010). High-Tech Architecture: Airport Design: Terminal Penumpang Bandar Udara Komersial Domestik. UIN MALIKI PRESS.

Davies, C. (1989). High Tech Architecture. Thames \& Hudson Ltd.

Ernawati, A. (2010). Perencanaan Superblok Sebagai Model Pengembangan Pembangunan Pusat Kota Bekasi. Jurnal Ilmiah Faktor Exacta, 3(1), 54-62.

Forilma, N. F., S, B. S., \& Pamungkas, S. T. (2016). Ekspresi Estetika Struktur Pada Stadion Sepakbola Arema Malang. 2, 8 .

Hanafi. (2017). Konsep Penelitian R \& D Dalam Bidang Pendidikan. Saintifika Islamica: Jurnal Kajian Keislaman, 4(2), 129-150. 
Haryati, S. (2012). Research And Development (R\&D) Sebagai Salah Satu Model Penelitian Dalam Bidang Pendidikan. 37(1), 11-26.

Jenks, C. (1988). The Battle Of High-Tech: Great Buildings With Great Faults. London, In Architectural Design.

Kuhlmann, D. (2011). Biomorphism In Architecture: Speculations On Growth And Form. Springer Berlin Heidelberg.

Rahayu, I., Wasilah, \& Darmawan. (2017). Arena Olahraga Ekstrim Dengan Pendekatan Arsitektur High Tech Di Makassar. Nature, 4, 39-48. 